\title{
High Sensitive Temperature Sensor Using a Liquid-core Optical Fiber with Small Refractive Index Difference Between Core and Cladding Materials
}

\author{
Yonghao Xu, Xianfeng Chen * and Yu Zhu \\ Department of Physics, the State Key Laboratory on Fiber Optic Local Area Communication Networks \\ and Advanced Optical Communication Systems, Shanghai Jiao Tong University, 800, Dong Chuan \\ Road, Shanghai, 200240, China
}

* Author to whom correspondence should be addressed; E-mail: xfchen@sjtu.edu.cn

Received: 29 November 2007 / Accepted: 21 February 2008 / Published: 17 March 2008

\begin{abstract}
An intensive temperature sensor based on a liquid-core optical fiber has been demonstrated for the measuring the temperature of the environment. The core of fiber is filled with a mixture of toluene and chloroform in order to make the refractive index of the liquid-core and the cladding of the fiber close. The experiment shows that a temperature sensitivity of about $5 \mathrm{~dB} / \mathrm{K}$ and a tunable temperature range (from $20{ }^{\circ} \mathrm{C}$ to $60{ }^{\circ} \mathrm{C}$ ) can be achieved. Based on the dielectric-clad liquid core fiber model, a simulation was carried out and the calculated results were in good accord with the experimental measurement.
\end{abstract}

Keywords: Temperature sensor, liquid-core fiber, sensitivity, mixture

\section{Introduction}

Fiber-optical sensors have been developed in a lot of fields for many decades. They were widely used in the measurement for temperature, strain, voltage, electric current, vibration and so on [1-9]. Of all these sensors, intensity-modulated fiber-optic sensors usually combine the lowest cost with the simplest structure. In 1967, Kissinger and Frank first proposed the reflectometry intensity-modulated fiber-optic sensor. From then on, the intensity-modulated fiber-optics sensors have been applied in the measurement of all kinds of parameters such as temperature, displacement, pressure, refractive and so on [10-13]. Since 1960, a variety of fiber-optical sensors have been invented. Nowadays, optic-sensors can be classified depending on the different fiber materials or fiber structure, such as the traditional 
SMF, the birefringence fiber, the lanthanum doped fiber and the sub-wavelength fiber and microstructure optical fiber [14-17] in the recently years.

Liquid-core optical fiber (LCOF) is a different structure fiber which has been investigated since 1972 [18]. A hollow fiber was filled with certain kinds of high index liquids to form the LCOF. In 1982, Kuribara and Takeda used hollow-core fibers filled with Kerr liquids for voltage measurements [19]. In 1983, a distributed temperature measured technique based on time domain reflectometry techniques was presented [20]. A measurement accuracy of $1^{\circ} \mathrm{C}$ with a spatial resolution of $1 \mathrm{~m}$ is attainable over a fiber length of $100 \mathrm{~m}$ and consequently, a sensitivity of $2.3 \times 10^{-2} \mathrm{~dB} /{ }^{\circ} \mathrm{C}(0.54$ percent ${ }^{\circ} \mathrm{C}^{-1}$ ) was observed. In 1991, Marten de Vries et al. first developed the liquid-core fiber temperature sensor [21], with a resolution of $0.2^{\circ} \mathrm{C}$ and a temperature range from $20^{\circ} \mathrm{C}$ to $185^{\circ} \mathrm{C}$. However the sensitivity is low (about $7 \times 10^{-3} \mathrm{~dB} /{ }^{\circ} \mathrm{C}$ ) at room temperature, which is hard to detect.

\section{Experimental Section}

\subsection{LCOF sensor fabrication}

In this paper, we present a new kind of temperature sensor based on the intensity-modulated principle. A hollow optical fiber is filled with a mixture of toluene and chloroform to form the LCOF. This kind of sensor has a high sensitivity in accurate temperature measurements and a tunable operational range, including room temperature, by simply changing the concentration of the two components. Practically, it also has an advantage of simplicity and low cost.

The sensor fiber is made of a hollow core silica fiber protected by a polyimide coating. The fiber can be commercially obtained with an inner core diameter of $250 \mu \mathrm{m}$. In order to get a tight confinement ability, the diameter of the hollow core is stretched from $250 \mu \mathrm{m}$ to $50 \mu \mathrm{m}$. Using a high pressure syringe system, the coated hollow fiber is filled with the liquid mixture, whose refractive index is a little higher than the silica clad. The low losses of the LCOF have been reported before [22].

\subsection{Experiment setup}

The configuration of the liquid-core optical fiber temperature sensor is shown in Figure 1. The light source is a tunable laser emitting continuous pulse of $1 \mathrm{mw}$ power at a wavelength around $1550 \mathrm{~nm}$. The laser is projected into the lead fiber of the sensor. The output of the sensor is directed through the lead fiber directly into the power meter. The two lead fibers are all inserted into the coating-stripped LCOF and the joint thus forms the sensor. The two lead fibers (A and C) are held at room temperature, whereas the LCOF part can be temperature-controlled. The temperature surrounding the LCOF is applied through a heated bath made by ourselves so that uniform temperature changes are insured. 
Figure 1. Experiment setup for the liquid-core fiber temperature sensor.

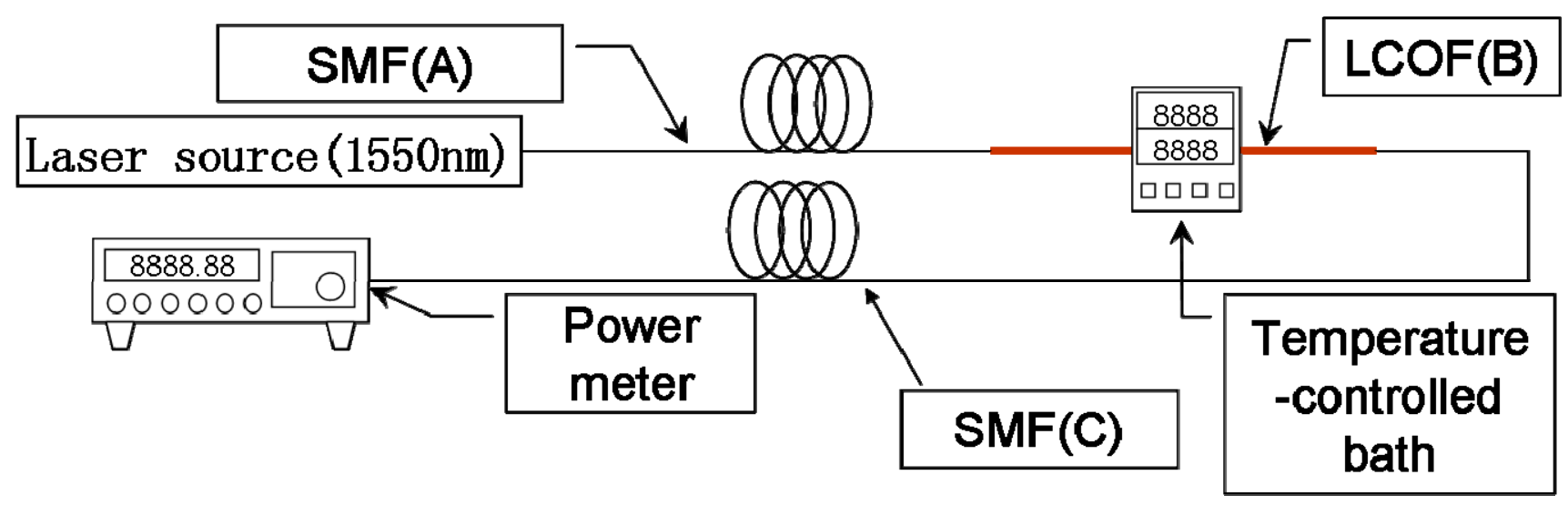

\subsection{Results}

Experimental results obtained from the setup are shown in Figure 2. In this experiment, mixtures with three different toluene concentrations which are separately 30\%, 37.5\%, 45\% were applied. As the temperature is increased, the refractive index of the mixture decreased in a near linear fashion. When the refractive index approaches the index of the silica cladding, the propagation efficiency $(\eta)$ decreases so that the intensity of the output decreases, too. Once the refractive index of the liquid core equal or smaller than the refractive of the silica cladding, no more light propagates through the fiber because the waveguide condition can not be met.

Figure 2. Variation of normalized transmitted intensity as a function of the temperature for liquid mixture with three kinds of concentrations of the toluene.

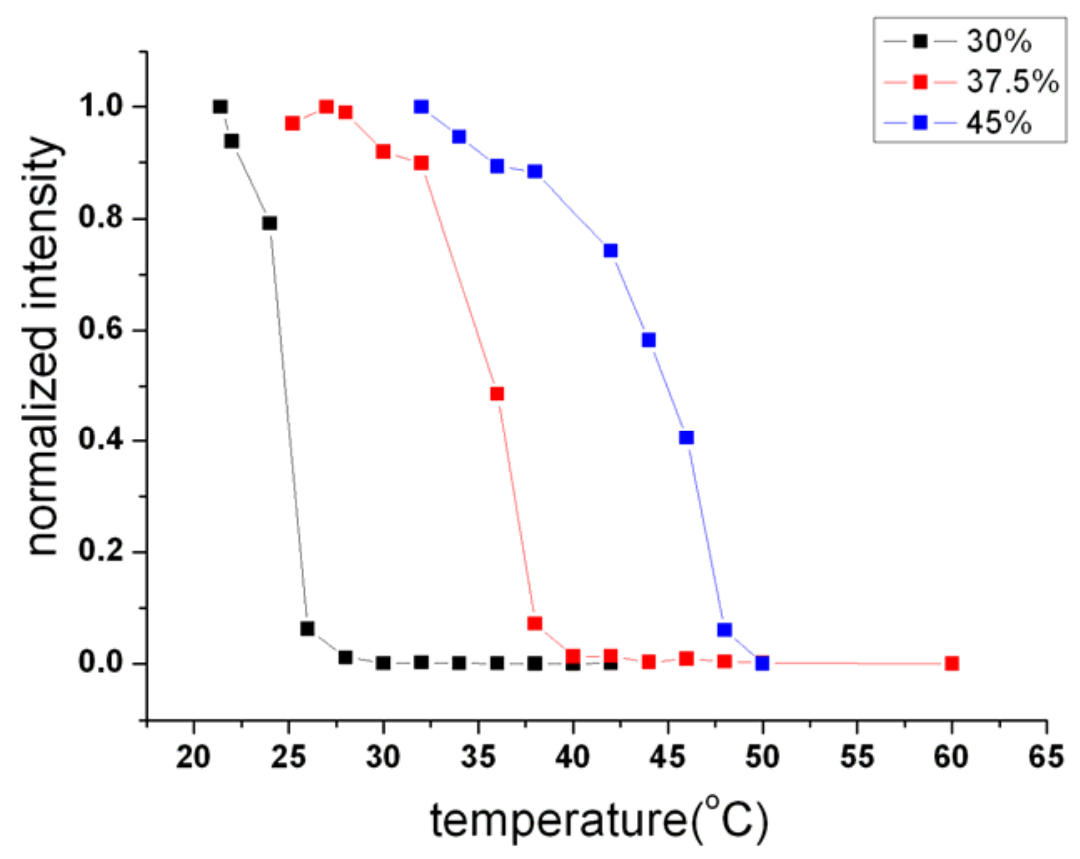


In Figure 2, when the concentration of the toluene is 30\%, the linear sensitivity range is seen to be from $22^{\circ} \mathrm{C}$ to $26^{\circ} \mathrm{C}$. The sensitivity of the sensor is about $5 \mathrm{~dB} / \mathrm{K}$. By adjusting the different concentration of the mixture, the different measurement range can be obtained. For the liquid with $37.5 \%$ toluene concentration, the range measured would be from $33^{\circ} \mathrm{C}$ to $37^{\circ} \mathrm{C}$ and also have the sensitivity $5 \mathrm{~dB} / \mathrm{K}$. When the liquid with $45 \%$ toluene concentration is used, the measured range from $41^{\circ} \mathrm{C}$ to $47^{\circ} \mathrm{C}$ can be obtained with the sensitivity $4 \mathrm{~dB} / \mathrm{K}^{-1}$. And similarly, in other operational range, the sensor's sensitivity should around $4-5 \mathrm{~dB} / \mathrm{K}$. Such device is much sensitive, comparing to other temperature sensor as reported. [23]

\section{Discussions and Conclusions}

\subsection{Simulation of the experiment}

The mathematic model in our simulation is a cylindrical structure involving two regions: A liquid core with radius $a$ and the infinite silica cladding. In our calculations, based on weakly-guiding theory, we ignore the length of the sensor fiber. Refractive indices of the liquid core (the mixture between toluene and chloroform) and the silica cladding are $n_{2}, n_{1}$, respectively. From the measured data [24], Sellmeier equations (1) were listed as follows at $20^{\circ} \mathrm{C}$.

$$
\begin{aligned}
& n_{\text {toluene }}=1.474775+0.0699031 / \lambda^{2}+2.1776 \times 10^{-4} / \lambda^{4} ; \\
& n_{\text {chloroform }}=1.431364+0.0563241 / \lambda^{2}-2.0805 \times 10^{-4} / \lambda^{4}+1.2613 \times 10^{-5} / \lambda^{6} ;
\end{aligned}
$$

and the Sellmeier equation (2) for $\mathrm{SiO}_{2}$ is:

$$
n_{\text {sio }_{2}}=1+\frac{0.6961663 \lambda^{2}}{\lambda^{2}-(0.0684043)^{2}}+\frac{0.4079426 \lambda^{2}}{\lambda^{2}-(0.1162414)^{2}}+\frac{0.8974794 \lambda^{2}}{\lambda^{2}-(9.896161)^{2}} ;
$$

By mixing the two liquids, we create a waveguide core of refractive index ranging from $n_{\text {toluene }}$ to $n_{\text {chloroform }}$. The relation between the refractive index of the mixed liquid $n_{\text {mixture }}$ and the concentration of toluene in the mixture $\rho$ is unknown and needed to be measured. Generally, the refractive index of the mixed liquid $n_{\text {mixture }}$ as a function of the concentration of toluene in the mixture $\rho$ can be expressed as the following equation (3) while considering the effect of temperature $T$ :

$$
\begin{aligned}
n_{\text {mixture }}= & {\left[\left.n_{\text {toluene }}\right|_{T=20^{\circ} \mathrm{C}}+d n_{\text {toluene }} / d T \times(T-20)\right] \times f(\rho) } \\
& +\left[\left.n_{\text {chloroform }}\right|_{T=20^{\circ} \mathrm{C}}+d n_{\text {chloroform }} / d t \times(T-20)\right] \times g(1-\rho) ;
\end{aligned}
$$

where $\mathrm{dn}_{\text {toluene }} / \mathrm{dT}=-5.273 \times 10^{-4}, \mathrm{dn}_{\text {chloroform }} / \mathrm{dt}=-6.328 \times 10^{-4}$ are the thermal coefficients of the refractive indices.

We also should consider the effect of $T$ to the coating material. Thus, the refractive index of the $\mathrm{SiO}_{2}$ should be expressed as follows:

$$
n_{\mathrm{SiO}_{2}}=\left.n_{\mathrm{SiO}_{2}}\right|_{T=20^{\circ} \mathrm{C}}+d n_{\mathrm{SiO}_{2}} / d T \times(T-20),
$$

From [25], $\mathrm{dn}_{\mathrm{SiO}_{2}} / \mathrm{dT} \sim-4 \times 10^{-6}$, which shows that the thermal coefficient of the $\mathrm{SiO}_{2}$ is much more less than the liquids. Furthermore, in our experiment, the range of the changing temperature is 
limited.(about $40^{\circ} \mathrm{C}$ ) For these two reasons, $n_{\text {sio }_{2}}$ can be seen as independent on temperature. The propagation efficiency $(\eta)$ can be obtained with the equation (5).

$$
\eta=\frac{N_{\text {core }}}{N_{\text {core }}+N_{\text {cladding }}},
$$

where $\mathrm{N}$ is the energy flow of light in the core and cladding region.

Because the index and the thermal coefficients of the mixture liquid are between those of toluene and chloroform, to simplify the process of simulation, we assume that $f(\rho)=\rho ; g(1-\rho)=1-\rho$, which under the assumption that the index of the mixture is linear with the concentration of the toluene. The simulation result is presented in the Figure 3. It shows that the experimental result accords with that of simulation well in the trend, and match the line well. It is should be noted that this assumption have little influence on the conclusions. In actual applications, the temperature dependence of refractive index at various concentrations should be measured.

Figure 3. Comparison of theoretical and experimental results (the concentration of the toluene is $30 \%$ ).

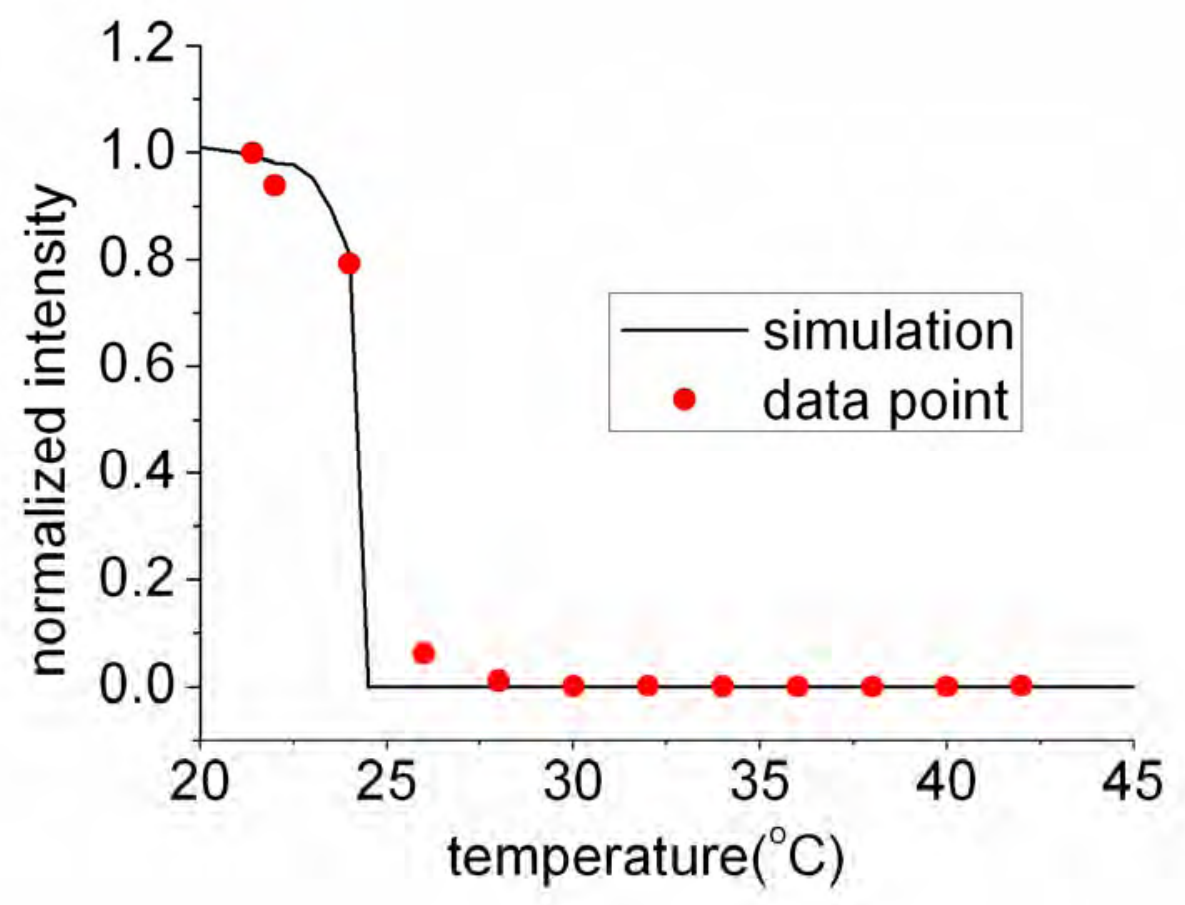

\subsection{Conclusions}

In summary, a type of intensive based liquid core optical fiber temperature sensor has been proposed. The mixture of toluene and chloroform was pumped into the hollow fiber to form the liquidcore optical fiber. By adjusting the concentration of the liquid, different ranges of the temperature sensor can be realized. Experimentally, the sensor was found to have a sensitivity of $4 \mathrm{~dB} / \mathrm{K}^{-1}$ to 5 $\mathrm{dB} / \mathrm{K}^{-1}$ over the temperature range $20-60^{\circ} \mathrm{C}$. Moreover the simple construction of this sensor shows an advantage in practical application. 


\section{Acknowledgements}

This research was supported by the National Natural Science Foundation of China (No. 10574092); the National Basic Research Program “973” of China (No. 2007CB307000 and 2006CB806000);

\section{References and Notes}

1. Giallorenzi, T.; Bucaro, J.; Dandridge, A.; Sigel, G.; Cole, J.; Rashleigh, S.; Priest, R. Optical fiber sensor technology. J. Quant. Electron. 1982, 18, 626-665.

2. Gottlieb, M.; Brand, G. B. Fiber-optic temperature sensor based on internally generated thermal radiation. Appl. Opt. 1981, 20, 3408-3417.

3. Gottlieb, M.; Brand, G. B. Temperature sensing in optical fibers using cladding and jacket loss effects. Appl. Opt. 1981, 20, 3867-3873.

4. Jones, B. E. Optical fiber sensors and systems for industry. J. Phys. E. 1985, 18, 770-782.

5. Polynkin, P.; Polynkin, A.; Peyghambarian, N.; Mansuripur, M. Evanescent field-based optical fiber sensing device for measuring the refractive index of liquids in microfluidic channels. Opt. Lett. 2005, 30, 1273-1275.

6. Adamovsky, G. Fiber-optic displacement sensor with temporally separated signal and reference channels. Appl. Opt. 1988, 27, 1313-1315.

7. Minkovich, V.; Villatoro, J.; Monzón-Hernández, D.; Calixto, S.; Sotsky, A.; Sotskaya, L. Holey fiber tapers with resonance transmission for high-resolution refractive index sensing. Opt. Express 2005, 13, 7609-7614.

8. Monro, T. M.; Belardi, W.; Furusawa, K.; Bagget, J. C.; Broderick, N. G. R.; Richardson, D. J. Sensing with microstructured optical fibers. Meas. Sci. Technol. 2001, 12, 854-858.

9. Adamovsky, G. Fiber-optic displacement sensor with temporally separated signal and reference channels. Appl. Opt. 1988, 27, 1313-1316.

10. Bertholds, A.; Dandliker, R. Deformation of single-mode optical fibers under static longitudinal stress. J. Lightwave Technol. 1987, 5, 895-900.

11. Adamovsky, G.; Piltch, N. D. Fiber-optic thermometer using temperature dependent absorption broadband detection, and time domain referencing. Appl. Opt. 1986, 25, 4439- 4444.

12. Johnstone, W.; Thursby, G.; Moodie, D.; McCallion, K. Fiber-optic refractometer that utilizes multimode waveguide overlay devices. Opt. Lett. 1992, 17, 1538-1541.

13. Sheem, S. K.; Cole, J. H. Acoustic sensitivity of single-mode optical power dividers. Opt. Lett. 1979, 4, 322-325.

14. Lou, J.; Tong, L.; Ye, Z. Modeling of silica nanowires for optical sensing. Opt. Express 2005, 13, 2135-2140.

15. Villatoro, J.; Monzón-Hernández, D. Fast detection of hydrogen with nano fiber tapers coated with ultra thin palladium layers. Opt. Express 2005, 13, 5087-5092.

16. Villatoro, J.; Monzón-Hernández, D.; Talavera, D. High resolution refractive index sensing with cladded multimode tapered optical fiber, Electron. Lett. 2004, 40, 106-107.

17. Minkovich, V. P.; Monzón-Hernández, D.; Villatoro, J.; Badenes, G. Microstructured optical fiber coated with thin films for gas and chemical sensing. Opt. Express 2006, 14, 8413-8418. 
18. Stone, J. Optical transmission loss in liquid-core hollow fibers. J. Quant. Electron. 1972, 8, 386388.

19. Kuribara, M.; Takeda, Y. Liquid core optical fiber for voltage measurement using Kerr effect. Electron. Lett. 1983, 19, 133-135.

20. Hartog, A. A distributed temperature sensor based on liquid-core optical fibers. J. Lightwave Technol. 1983, LT-1, 498-509.

21. deVries, M., Zimmermann, B. D., Vengsarkar, A. M.; Claus, R. O. Liquid core optical fiber temperature sensors. IEEE Region 3 Technical Conference, Huntsville (USA), 2003; pp 11351138

22. Payne, D.N.; Gambling, W.A. New low-loss liquid core fiber waveguide. Electron. Lett. 1972, 8, 374-376.

23. Hartog, H. A distributed temperature sensor based on liquid-core optical fibers. J. Lightwave Technol., LT-1, 498-509(1983)

24. Samoc, A. Dispersion of refractive properties of solvents: Chloroform, toluene, benzene, and carbon disulfide in ultraviolet, visible, and near-infrared. J. Appl.Phys. 2003, 94, 6167-6174.

25. Weber, M. J. In Handbook of Optical Materials. CRC Press: Boca Rtaon, FL, 2003; pp. 93-105.

(C) 2008 by MDPI (http://www.mdpi.org). Reproduction is permitted for noncommercial purposes. 